\title{
Dixit. Gra filozoficzna zamiast gamingu
}

\author{
Mariusz Mazurkiewicz (Uniwersytet im. Adama Mickiewicza)
}

Grę Dixit zaprojektował Jean-Louis Roubir, wzory kart opracowałą Marie Cardouat. Trafiła ona na rynek - i dość szybko także do warsztatu dydaktycznego sporej liczby nauczycieli - w 2008 roku za sprawą francuskiego producenta Libellud ${ }^{1}$. W Polsce grę wypuściło na rynek wydawnictwo Hobbity.eu. Gra została uhonorowana kilkoma nagrodami, m.in. nagrodą As d'Or 2009, co oznacza, że została ona uznana za Grę Roku we Francji na Międzynarodowym Festiwalu Gier w Cannes 2009; w 2010 roku wybrana została również grą roku w Niemczech, Spiel des Jahres 2010 Kritikerpreis.

W dobie powszechnie dostępnego gamingu, wielkiej różnorodności i tempa rozwoju interaktywnej oraz interfejsowej oferty gier, codziennej dostępności ipadów i tabletów zainteresowanie uczniów lekcją na żywo bywa coraz trudniejsze. Zwłaszcza gdy chodzi o zajęcia, w których uczeń sam decyduje czy chce w nich uczestniczyć czy nie. Przykładem może być etyka lub filozofia; na zajęciach $\mathrm{z}$ tych przedmiotów, pomimo dobrowolnego uczestnictwa, pojawia się tematyka nie mniej ważna od tej nauczanej obligatoryjnie. Cechą specyficzną etyki jest uruchamianie przez nią indywidualnego oglądu problemów społecznych, procesów logicznego namysłu, rozumienia i rozstrzygania w oparciu o kryteria wartości, normy, które dzieci wykorzystują do uzasadniania swych osądów i rozwiązań. Liczą się tutaj najrozmaitsze sprawności, zwane inaczej kompetencjami; sama wiedza i informacja odtwarzane na podstawie podręczników nie wystarczą. Wielu nauczycieli etyki staje przed dylematem, czy prowadzić z uczniami bardziej swobodne lekcje polegające głównie na zabawie przeplatanej refleksją i wypowiedzią, czy raczej sążniste, merytoryczne wykłady i pogadanki, dzięki którym uczeń wyniesie $\mathrm{z}$ lekcji wiedzę na temat konkretnych 'koncepcji' w etyce; można i należy wprowadzać 15-minutowe fazy takiej dydaktyki. Z kolei zbyt dowolny charakter zajęć może sprawić, że zajęcia można potraktować 'lekko'; znów dobrowolność uczestniczenia może spowodować, iż dojdą do wniosku, że skoro na kolejnym przedmiocie wymaga się od nich słuchania skomplikowanych i nużących wykładów, i po prostu z niego po prostu zrezygnują. W zajęciach - także, a może nawet zwłaszcza $\mathrm{z}$ etyki i filozofii - muszą więc kryć się wyzwania i zadania, na przemian z refleksją wspierającą ze strony nauczyciela. Toteż zajmująco prowadzone

1 Informacje dostępne na stronie WWW: <http://www.libellud.com> oraz <http://www.libellud.com/jeux/dixit>; dostęp: 19.02.2014. 
'luźne' zajęcia mogą również rozwijać kompetencje intelektualne, moralne i dyskursywne, ponieważ nie ma groźniejszego 'killera' dla tych kompetencji aniżeli nudna, monotonna i przymusowa lekcja. Można jednak urozmaicić przekaz połączyć dobrą zabawę z dużą dawką wiedzy merytorycznej i kompetencji /sprawności/ praktycznych, które uczeń może zdobyć podczas lekcji; pretekstem i medium służącym ich rozwojowi mogą być gry filozoficzne.

Jedną z nich jest gra planszowa Dixit, która doskonale łączy stymulację $\mathrm{w}$ konwencji zabawowej $\mathrm{z}$ rozwojem umysłowym, w tym - rozwojem wyobraźni, kreatywnego i krytycznego myślenia, a także rozwojem umiejętności społecznych i - co bardzo istotne - wzrostem poczucia przynależności do grupy i wreszcie stopniem integracji grupy, widocznym również z perspektywy nauczyciela i ułatwiającej $\mathrm{w}$ efekcie cały proces dydaktyczny; wreszcie sprawia ona, że uczeń chętniej bierze udział w lekcji i pozytywniej postrzega swoje szkolne życie. Z racji przejrzystej konstrukcji może być używana na każdym etapie edukacyjnym. Zanim przejdę do szczegółowej analizy gry pod względem jej przydatności na lekcjach filozofii i etyki, kilka słów o samej grze. Istnieją dwie wersje gry - pierwsza,

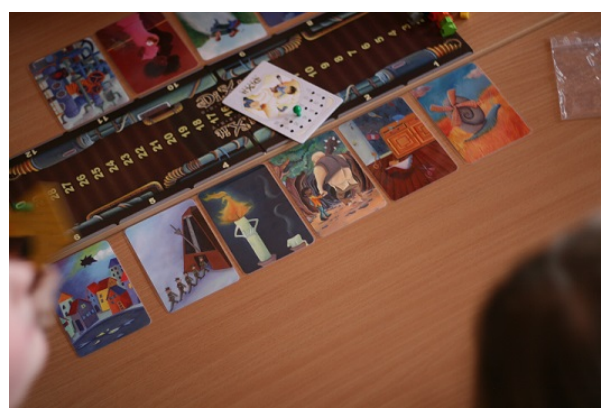

Rys. 1 Przykładowe karty do gry podstawowa, zwana Dixit i druga, rozszerzona i wzbogacona, zwana DixitOdyssey. Różnią się one od siebie ilością uczestników; w pierwszej uczestniczyć może maksymalnie 6 osób, w rozszerzonej zaś - dwukrotnie tyle, tj. 12 osób. Gra składa się $\mathrm{z}$ osiemdziesięciu czterech kolorowych kart, opatrzonych różnobarwnymi, często abstrakcyjnymi obrazkami w konwencji piktograficznej. To one właśnie nadają grze niezwykły charakter sprawiając, że gra jest również niezwykłym wyzwaniem dla umysłu. Dodatkowego uroku grze (co zauważyłem podczas zajęć z uczniami, w których ją stosowałem) przysparzają różnobarwne 'króliczki', które pełnią rolę pionków umożliwiających uczestnikom kontrolowanie ich ruchów na widocznej dla wszystkich planszy. Zasady gry są proste, dzięki czemu uczniowie szybko nabierają orientacji, o co chodzi w grze. Każdy gracz otrzymuje losowo 6 kart, których nikomu nie pokazuje. Pierwszy z uczniów, który wpadnie na skojarzenie resp. hasło powiązane z jedną, dowolną spośród jego kart, inicjuje grę - sygnalizując, że 'ma' skojarzenie. Wypowiada je głośno, komunikując pozostałym uczestników. Ci z kolei mają za zadanie odnaleźć w swojej talii kartę najbardziej zbliżoną, odpowiadającą podanemu hasłu, po czym oddają tę kartę narratorowi (jest nim gracz, który jako pierwszy podał hasło w rundzie). Narrator tasuje karty i wykłada je, odkrywając. Uczestnicy (z wyłączeniem narratora) muszą zgadnąć, która z kart należy do narratora, oraz podać cyfry ze swoich 'znaczników' 
(kartoników z cyferkami do głosowania, które otrzymali wcześniej). Następnie podliczają punkty $\mathrm{w}$ zgodzie $\mathrm{z}$ opisem podanym $\mathrm{w}$ instrukcji, a wreszcie przesuwają króliki na planszy o tyle miejsc, ile punktów właśnie zdobyli. Następnie każdy dobiera sobie po jednej karcie ze stosu wyłożonych, zakrytych kart, uzupełniając swój zestaw (musi on być po każdej rundzie taki sam, jak na początku gry). Rundy następują zgodnie z ruchem wskazówek zegara. Gra toczy się aż do wyczerpania kart ze stosu i talii, jakie posiadają uczestnicy.

Podczas gry żaden z uczniów nie pozostaje bezczynny. W każdym momencie uczniowie wykonują jakieś zadania, wymyślają i układają hasła, obserwują karty, głosują na odpowiednią kartę, budują osądy i podejmują decyzje; mają poczucie włączenia, udziału, odpowiedzialności i przede wszystkim - kooperują ze sobą na żywo. Odróżnia to Dixit od komputerowego gamingu, który funkcjonuje na zupełnie innych zasadach choćby dlatego, że nie konfrontuje ze sobą graczy na żywo, twarzą w twarz, w przestrzeni społecznego dialogu i gry. Na tym polega również społeczny i uspołeczniający walor Dixit. Atrakcyjność gry polega więc nie tylko na barwnych, pełnych piktogramów i obrazów kartach 'zapraszających' niejako do gry, budzących niezliczoną ilość skojarzeń. Zajmujące umysł, wyobraźnię i wiele umiejętności poznawczych gry nie muszą i nigdy nie były zbyt złożone i rozbudowane - gry mogą być schematyczne i niezwykle proste, ponieważ cała konstrukcja operacji i sytuacji, jaką inicjuje gra, jest dziełem aktywności umysłowej uczestników. Gra w rodzaju Dixit sprawiają, że żaden uczeń nie czuje się pominięty ani przegrany - ponieważ przegrana w głosowaniu tak czy inaczej pozostaje udziałem i partycypacją $\mathrm{w}$ grze. Wszyscy w równym stopniu mają szansę partycypować. W grze pojawiają się rzecz jasna tymczasowo wygrani i przegrani - najważniejsze są jednak partycypacja, pasja i ciekawość rozwoju sytuacji. Uczniowie angażują się oczywiście w sposób konkurencyjny, jednak nie jest to jedyni ani zasadniczo dominujący aspekt gry. Poprzez partię gry, poprzez rozgrywkę, w której uczestniczą, trenują kreatywne myślenie, uczą się sprawnie i szybko podejmować wyzwania i rozwiązywać zadania. Uczą się także doceniać pomysłowość oraz współpracę w całej grupie. Dzięki silnie włączającemu, a nie - eliminującemu, a ponadto - koedukacyjnemu charakterowi gry uczniowie mają szansę 'zgrać' się i poczuć wspólnotą. Uczniowie wyłączeni lub wycofani z jakichkolwiek powodów, niezależnych od lekcji i cyklu edukacyjnego prowadzonego przez nauczyciela otrzymują szansę stopniowego zintegrowania się z grupą. Nie muszą w pojedynkę starać się o przyjęcie do niej; grupa spontanicznie otwiera się dla nich, a integracja staje się niewymuszona i naturalna.

Na lekcjach, po zapoznaniu uczniów ze standardowymi regułami gry, możemy im zaproponować wariant etyczny tej samej gry. Dzięki przygotowaniu różnorakich cytatów dotyczących sytuacji walentnych etycznie czy sentencji filozofów, dzieci mogą się przygotować do interpretacji 
piktogramów lub ilustracji. Nauczyciel możne również stworzyć własne rozszerzenie gry poprzez cykl piktogramów kojarzących się etycznie, interkulturowo itp. Taka alternatywa może stymulować opanowanie i operacjonalizację nowych pojęć $\mathrm{z}$ zakresu etyki. Wreszcie sami uczniowie mogą zaprojektować własne karty $\mathrm{z}$ piktogramami i schematami. W tego

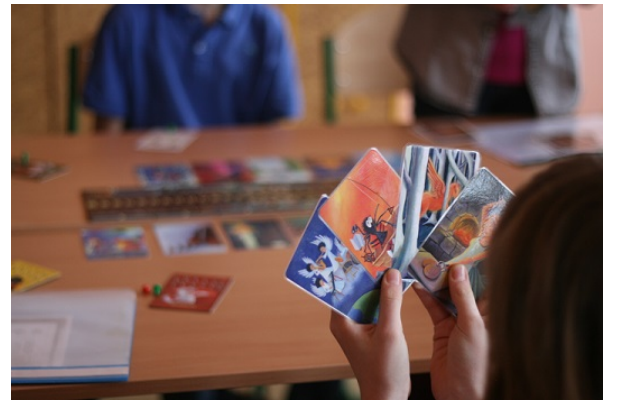

Rys. 2 Uczniowie podczas zabawy rodzaju warsztatach każdy z uczniów może więc wyrazić swą indywidualność w sposób kreatywny, komunikatywny, zapraszający do 'gry' innych. Gra jest może być doskonałą rozgrzewką podczas standardowych lekcji. Autor wykorzystuje ją na lekcjach etyki, które z natury rzeczy dalekie są od nudy po to, by wypróbować jej skuteczność, a także zrównoważyć wpływ cywilizacji cyfrowo-medialno-wizualnej i zachęcić młodzież do myślenia w sposób, który będzie dla niech atrakcyjny i w jakiejś mierze już oswojony. Gra okazuje się do tego stopnia atrakcyjna, że wielu uczniom żal opuścić klasę na czas przerwy międzylekcyjnej. Istnieje oczywiście typ organizacji zajęć szkolnych, w którym uczniowie sami decydują, kiedy potrzebują przerwy - to jednak pozostaje kwestią kierunku, w jakim rozwijać się będzie organizacja procesu nauczania w polskim szkolnictwie publicznym.

Poniżej uczniowski feedback na temat doświadczeń z grą Dixit podczas zajęć prowadzonych tą metodą przez autora raportu.

Dixit to bardzo fajny sposób na spędzenie czasu. Trzeba było trochę pomyśleć i pokazać się z kreatywnej strony. Ciekawie się grało dlatego, że każdy odbierał obrazki inaczej i czasem trzeba było naprawdę się postarać żeby zgadnąć [Weronika, lat 12].

Bardzo fajna gra uczy kreatywności i uczciwości. Gra jest prosta ale trzeba zrozumieć zasady i być pomysłowym i przewidującym. Czasami dziwię się jakie ktoś hasła wymyśla. To jest super króliki rządzą [Marianna, lat 12].

Dzięki tej grze nauczyłam się, że można dobrze się bawić i się uczyć. Nauczyłam się też lepiej opisywać i zgadywać obrazki [Alicja, lat 12].

Dixit jest świetną grą. Rozwija umiejętności kreatywnego myślenia, skojarzenia podczas gry były różne. Mam nadzieje, że jeszcze w to zagramy [Basia, lat 12].

Kiedy po raz pierwszy grałem w Dixit pomyślałem - co za skomplikowana gra, jednak myliłem się [Dominik, lat 13]. 
Według mnie Dixit jest fajny. Miałem wiele wyobrażeń kart, ocena 10/10" [Mateusz, lat 11].

Powyższy feedback świadczy o pozytywnym przyjęciu i prawdziwym zaangażowaniu dzieci w grę. Naturalne wśród dzieci wydają się początkowe reakcje na ilustracje, piktogramy itd. - tej swobodnej gry wyobraźni, która wiąże się też ze spontanicznym zadziwieniem - elementem niezwykle istotnym w edukacji filozoficznej i etycznej - a także rozbawieniem - nie należy sztucznie hamować. Z czasem reakcje stają się bardziej refleksyjne, a grę wyobraźni zastępuje coraz częściej refleksja i praca polegająca na pojmowaniu i tworzeniu pojęć $\mathrm{w}$ odpowiedzi na wyzwania i pytania, podyktowane grą. "Pojęcie jest budulcem myślenia... Co dokładnie rozumiesz przez.... " [Steenblock 2013, 157] - to akt filozofowania, który może być uruchamiany $\mathrm{w}$ medium schematycznego, w dużej mierze abstrakcyjnego, pozbawionego dosłowności języka ilustracji lub piktogramów. Z języka tego uczestnicy niepostrzeżenie przechodzą na poziom refleksji pojęciowej zaczynają bowiem myśleć, tworzyć konstrukcje intelektualne, budować spójne i adekwatne wypowiedzi, dobierając coraz bardziej precyzyjne i trafne pojęcia, ucząc się odróżniać i kontrolować ich wagę, hierarchizować je i używać ich w sposób coraz bardziej świadomy i odpowiedzialny. W obliczu karty z ilustracją uczestnicy proponują nie tyle 'pierwszą lepszą' interpretację, ile interpretację najlepszą, jaką zdołał wytworzyć ich umysł. W ten sposób samodzielnie nadają sens i znaczenie temu, co zobaczyli, a także argumentują. Ich interpretacje i akty sensotwórcze - które za sprawą wypowiedzi stają się świadome jednocześnie dla nich samych i dla innych uczestników, z którymi się komunikują - powinny być bowiem możliwie najbardziej przekonujące, aby 'trafić' i dopiero dzięki temu 'wygrać' rundę. Zatem to nie siła fizyczna, siła perswazji czy przemoc werbalna stanowią o mocy takiego argumentu, lecz jego wewnętrzna, immanentna treść, logiczna konstrukcja, odpowiedni sposób artykulacji. Odpowiedź na "fascynujące pytanie, czym jest kreatywność, nie wyczerpuje się w 'znajdowaniu' idei, lecz w kształtowaniu naszego myślenia i działania“" [Steenblock 2013, 161].

\section{Literatura}

Steenblock, V. 2013. Philosophische Bildung. Einführung in die Philosophiedidaktik und Handbuch Praktische Philosophie. Münsteraner Philosophische Arbeitsbücher. Münster: LIT Verlag. 
Mariusz Mazurkiewicz

\title{
Dixit. Gra filozoficzna zamiast gamingu
}

\begin{abstract}
This article presents an alternative way of organizing lessons using games. Dixit is a game that facilitates mental development, including development of imagination, creative and critical thinking, social skills, and of an increased sense of belonging to the group. It makes the student more willing to take part in lessons and positively perceive their school life. In the era of widely available gaming, great variety of interactive games, daily availability of iPads and tablets, students' interest in the lesson is sometimes more difficult. Especially when it concerns the activities in which the student decides whether he wants to attend. An example would be ethics or philosophy; on these lessons, although voluntary participation, there is a subject no less important than those taught compulsorily. The role of the teacher is to organize lessons for the student, which will encourage participation and facilitate the transfer of knowledge on the topic.
\end{abstract}

Keywords: gaming, Dixit, board games, lessons of ethics, education, philosophy

Ethics in Progress (ISSN 2084-9257). Vol. 4 (2013). No. 1. pp. 129-134. 